\title{
SYMPOSIUM ON THE LAW OF INTERNATIONAL CIVIL PROCEDURE IN ASIAN COUNTRIES
}

\section{Editorial note}

The topic of the present symposium is the outcome of a deliberate choice, giving expression to several considerations that underlay the initiative to start publication of the Yearbook.

Among these considerations is the perceived need to enhance the presentation of under-exposed Asian views and practices in the field of international law in a broad sense of the term. This includes law emanating from international sources as well as municipal law relating to transnational relationships. The latter encompasses both 'public' and 'private' matters, and includes, most eminently, the conflict of laws. The law on civil procedure of the various Asian countries relating to transnational relationships obviously also falls under the same category.

Another consideration is the need for jurists from the different Asian countries to familiarize themselves with each other's legal views and practices and thus to learn from the legal successes and failures of their neighbours, after having, for much too long indeed, focused their interest and attention almost exclusively on the law, institutions and policies of societies which are (far) more distant to their own in more than a merely geographic sense. From this point of view, the law on international civil procedure as the set of legal rules governing transnational litigation among private parties is an eminently practical, and consequently most suitable, field of the law to be taken as the subject matter of a comparative presentation.

The scope of the topic is, of course, very broad, certainly too broad for an exhaustive analysis of all relevant aspects of the subject. The paucity of existing expositions of the field as a whole in a commonly accessible form and language, however, has led us to the conclusion that the present first effort should offer a general survey as a starting point for further research and investigation.

The Editors have been most fortunate to be able to benefit from the expertise and experience of Professor KONO TOSHIYUKI who not only participated as one of the authors but who has acted as a Co-Editor for the present Symposium.

It is a matter of profound regret that it has not been possible to have scholars from more countries to participate in the symposium. However, the Yearbook welcomes contributions for additional 'national chapters', which may be published in its future Volumes, and thus enrich the discussion on the topic.

The Editors express the hope that the present symposium will serve as a reminder to those colleagues who regularly deal with transnational private law and international conflict of laws rather than public international law, that the Yearbook is theirs as well and should be used as the natural forum of communication and presentation of Asian aspects of their fields of expertise. 